Малюгин Дмитрий Васильевич Исследователь фундаментальных физических законов и явлений.

Россия, г. Ростов-на-Дону. 02.03.2016 год.

\title{
«Общая теория мироздания»
}

Аннотация: публикация «Общая теория мироздания» - это несколько новых теорий основанных на фактах и логических выводах, автором теорий Малюгиным Дмитрием Васильевичем. В «Общая теория мироздания» входят новые теории:

- теория гравитации;

- теория антигравитации;

- теория кинетической энергии;

- теория электромагнетизма;

- формулировка функции «время».

- Этот свод теорий также показывает несостоятельность «Общей теории относительности - Альберта Эйнштейна»

Каждый человек в своей жизни задумывался о принципах физических явлений, таких как:

- Гравитация;

- Чёрные дыры;

- Электричество;

- Магнетизм;

- Время...

Я, тоже не исключение.

Когда не могут объяснить такие обыденные физические явления, не только учителя в школах, но и люди, обладающие научной степенью. То неволей задумываешься - правильны ли общепринятые теории?

И я решил разобраться в этих вопросах, полагаясь только на факты и логическое мышление. Когда начал сопоставлять все факты, то понял - чтоб найти ответы на эти вопросы, нужно мыслить глобально, а не локально! 


\section{Вселенная.}

Что такое вселенная? - Я подразумеваю под этим вопросом:

- Какого она размера?

- Есть ли у неё края?

- Когда она возникла, и как?

- Из чего состоит вселенная?

- Почему космическое пространство темное и холодное, а звезды горят и испускают свет?

Тьма, в своём значении намного больше и сложнее, чем большинство людей о ней думают, «противопоставляя свет против тьмы».

Всё пространство вселенной состоит из мельчайших частиц, из которых создаётся энергия и материя. Объясню, почему я в этом уверен:

Если разместить на небольшом расстоянии, друг от друга, два мощных постоянных магнита, то в любом случае, они будут влиять друг на друга, даже если между ними поместить материал с высокой плотностью, или поместить их в глубокий вакуум, в котором по утверждению некоторых учёных «ничего нет». То есть, в любых условиях, на небольшом расстоянии друг от друга, между двумя постоянными магнитами, существует постоянная связь, тем самым, подтверждая, что видимая часть вселенной, заполнена сверхмалыми частицами, и не имеет в своём пространстве, полностью пустых участков, в которых ничего не происходит. И к этому утверждению есть неоспоримый факт: С любого места, видимой вселенной, можно увидеть бесчисленное окружение звёзд и галактик, которые излучают частицы света, создавая непрерывное движение сверхмалых частиц. Они летят в пространстве вселенной, по многочисленным траекториям, со световыми скоростями, врезаясь, и пролетая сквозь любые объекты, за исключением частиц, которые врезаются в ядра атомов, и, отражаясь под определёнными углами, разлетаются по разным траекториям.

- На вопрос - «Как появились звёзды, планеты и все остальные космические объекты вселенной?», только возможно, дать ответ в виде теории или гипотезы, так как на данный момент, нет никаких фактов указывающих для выявления истинного знания, создания вселенной.

Так как фактов нет, то, только полагаясь на логику, в моём мышлении структурировалась теория происхождения вселенной:

Изначально пространство нашей вселенной состояло только из сверхмалых частиц - из пространства, заполненного так называемым «эфиром». Эти сверхмалые частицы, имели равномерное распределение между собой, создавая однородную область давления в космическом пространстве. Далее, происходит некое действие, повлекшее образованию критической массы сверхмалых частиц, создавая сверхплотную материю, и последующему 
первому взрыву этой материи, с резким выбросом энергии в космическое пространство вселенной. И этот, первый взрыв стал «искрой жизни», создавший движение со скоростью света, создавая энергию и материю в нашей вселенной. «Искра жизни», была такой небольшой как «Большой взрыв», но её выброса энергии, хватило на то, чтоб ближайшие к взрыву сверхмалые частицы, вместе с энергией взрыва, разлетелись во все стороны со скоростью света. А далее: как снежный ком, увеличивается в своей массе, когда «летит» на большой скорости с заснеженного склона горы. Также, сверхмалые частицы, разогнанные до скоростей света, сталкиваясь с другими частицами, образовывали энергию и материю, из которой состоят галактики, звёзды, планеты, живые существа, наш разум, и всё остальное.

На данный момент, в пространстве вселенной, происходят бурные движения от самых малых частиц, до таких объектов как галактики. И Вселенная уже никогда не вернётся до изначального состояния.

На счёт вопроса о размере вселенной, скажу так: - Когда человечество найдёт способ увидеть самые маленькие частицы вселенной, то это будет, одно из двух, самых великих открытий человечества.

Второе великое открытие будет тогда, когда человечество узнает истинный размер нашей вселенной. Какое из этих двух открытий свершиться первым даже предположить не могу. Так как сверхмалые частицы, сами по себе самые маленькие во вселенной, но и ещё, относительно нас, не могут быть неподвижными, так как мы движемся в пространстве вселенной с космическими скоростями. А чтобы увидеть край вселенной, то нужно, чтоб у вселенной была граница! Тогда возникает вопрос: Что находится по ту сторону границы вселенной?

Хочется верить, что эти открытия всё же свершаться, даже если на это, человечеству понадобиться много миллионов лет. Человеческий разум должен стремиться к совершенству и обладанию всех истиннофундаментальных знаний, окружающей нас среды.

- Так как с размерами вселенной на данный момент можно только гадать, то отвечу, на такие вопросы, как: - Что такое тьма? И, что такое свет?

- Тьма - это космическое пространство вселенной. Можно сказать - среда обитания всех движущихся объектов вселенной. А космические объекты постоянно двигаются в космическом пространстве, и если перестанут двигаться в среде полностью заполненной сверхмалыми неподвижными частицами, то объекты потеряют межатомные связи, и станут распадаться на составляющие частицы, из которых они состоят. Здесь также подходит выражение - «движение - это жизнь».

Свет - это реакции (на уровне элементарных частиц), выбрасывающие в окружающую среду со скоростями света, группы сверхмалых частиц (фотоны). - Это ядерные реакции в звёздах, химический распад атомов 
вещества, или физическое влияние сконцентрированной окружающей среды, на атомы материи (свет от электрической лампы).

Взглянем на ближайшую к нам звезду по имени «Солнце». Эта звезда непрерывно излучает частицы света (фотоны), во все стороны от себя и часть этого потока фотонов, попадает на Землю, создавая дневной свет, при котором мы видим окружающую нас среду. Но если вылететь в открытый космос, и на некотором расстоянии от космонавта в скафандре, развернуть экранирующий материал, защищающий от попадания солнечных лучей. То оглянувшись по сторонам, космонавт не увидит яркого света, и не почувствует тепло - которое мы чувствуем своим телом в летние дни. Хотя, космонавт будет находиться намного ближе к Солнцу, чем человек находящийся на планете - стоящий в тени, укрываясь от попадания прямых солнечных лучей. Космонавту будет очень холодно, а вокруг него, будет полная темнота, и только будут видны далёкие звёзды, и объекты, которые отражают солнечный свет. Хотя космонавт будет находиться в плотном потоке фотонов, несущих свет.

Свет (фотоны) - это и есть тьма! Сверхмалые частицы излучаются группами, имеющие определённые характеристики: количество сверхмалых частиц, объём, форму, плотность, скорость движения, скорость и направления вращения, и т.п.

- Мы видим нашими глазами только те объекты, на поверхности которых, происходят реакции элементарных частиц, от которых со скоростями света летят фотоны. И также, видим объекты, в поверхность которых, врезаются со скоростями света фотоны. - Создавая реакции на уровне элементарных частиц с излучением ими фотонов с определёнными диапазонами света, то есть с определёнными характеристиками, которые меняются в зависимости от характеристик объекта, в который они врезаются. В следствии, в нашу сетчатку глаза, врезаются со скоростями света, потоки фотонов с определёнными характеристиками. И затем, в мозг передаются импульсы полученной энергии, со зрительного органа чувств. Далее, фиксируется и обрабатывается мозгом.

Делая из этого логический вывод можно с уверенностью утверждать падающие фотоны света на объекты, от них не отражаются путём отталкивания (отскакивания) от объекта. Так как фотон света - это частица, состоящая из группы сверхмалых частиц. А любой объект, летящий со скоростью света, при ударе об более плотное препятствие, разрушится с выбросом энергии. Фотон - это не теннисный шарик, который с лёгкостью отскакивает от стенки. Хотя, если теннисный шарик, запустить в стену со скоростью света, то явно он от неё не отскочит. 


\section{Гравитация.}

Что такое гравитация?

- Я долго искал ответы, задавая сам себе вопросы. И только когда понял, что нужно мыслить масштабно, а не по отдельности рассматривать каждый вопрос, сразу началась вырисовываться картина мироздания. В двух словах её не описать, но постараюсь объяснить более кратко простыми и понятливыми словами.

Когда в школе объясняли, что планеты солнечной системы вращаются вокруг Солнца и не разлетаются, и не притягиваются к звезде, из-за того, что сила притяжения Солнца, и центробежная сила планет, уравнивают друг друга, и по этому, планеты не слетают со своих орбит. На этот ответ, я вспомнил высказывание: Один раз - это случайность. Два - совпадение. А три раза - это уже, закономерность!

Так что же всем планетам подбирает такую скорость вращения вокруг Солнца, что они на протяжении тысячелетий не слетают со своих орбит?

- Мне самому интересно, что бы ответили учёные, поддерживающие общую теорию относительности, на такую логическую не состыковку.

Сравним параметры объектов солнечной системы:

\begin{tabular}{|c|c|c|c|c|c|c|c|c|c|c|}
\hline & Солнце & Меркурий & Венера & Земля & Mapc & Церера & Юпитер & Сатурн & Уран & Нептун \\
\hline Расстояние & & & & & & астероид & & & & \\
\hline $\begin{array}{c}\text { от Солнца } \\
\text { до планеты }\end{array}$ & & 58млн.кМ & 108мЛн.КМ & 149млн.км & 228млн.км & 414млн.Км & 778млн.км & 1.426млн.км & 2.877мЛн.КМ & 4.550млн.кМ \\
\hline Орбитальная & & & & & & & & & & \\
\hline $\begin{array}{c}\text { скорость планеты } \\
\text { вокруг Солнца } \\
\end{array}$ & & $47,9 \mathrm{Km} / \mathrm{c}$ & $35 \mathrm{~km} / \mathrm{c}$ & $29,8 \mathrm{~km} / \mathrm{c}$ & $24,1 \mathrm{~km} / \mathrm{c}$ & $17,9 \mathrm{~km} / \mathrm{c}$ & $13,1 \mathrm{~km} / \mathrm{c}$ & $9,7 \mathrm{~km} / \mathrm{c}$ & $6,8 \mathrm{~km} / \mathrm{c}$ & $5,4 \mathrm{~km} / \mathrm{c}$ \\
\hline \multirow{2}{*}{ Диаметр } & 1.391 .000 & 4.879 & 12.103 & 12.756 & 6.752 & 962 & 143.000 & 120.500 & 51.000 & 49.500 \\
\hline & KM & KM & KM & KM & KM & KM & $\mathrm{KM}$ & $\mathrm{KM}$ & $\mathrm{KM}$ & KM \\
\hline Полный оборот & вокруг своей & 88 & 225 & 365 & 1,9 & 4,6 & 11,9 & 29,5 & 84 & 164,8 \\
\hline вокруг Солнца & оси 25,4 сут. & суток & суток & суток & года & года & года & года & года & года \\
\hline
\end{tabular}

Здесь чётко прослеживаются закономерность!

Когда я решил взглянуть на солнечную систему в уменьшенном масштабе 1:1000000000, учитывая соотношения размеров и расстояний - вот, что получилось:

\begin{tabular}{|c|c|c|c|c|c|c|c|c|c|c|c|}
\hline & Солнце & Меркурий & Венера & Земля & Марс & $\begin{array}{c}\text { Церера } \\
\text { астероид }\end{array}$ & Юпитер & Сатурн & Уран & Нептун \\
\hline $\begin{array}{c}\text { Расстояние } \\
\text { от Солнца } \\
\text { до планеты }\end{array}$ & & 58 & 108 & 149 & 228 & 414 & 778 & 1.426 & 2.877 & 4.550 \\
\hline Диаметр & $139,1 \mathrm{~cm}$ & $0,5 \mathrm{~cm}$ & $1,2 \mathrm{~cm}$ & $1,3 \mathrm{~cm}$ & $0,7 \mathrm{~cm}$ & $0,1 \mathrm{~cm}$ & $14,3 \mathrm{~cm}$ & $12 \mathrm{~cm}$ & $5,1 \mathrm{~cm}$ & $5 \mathrm{~cm}$ \\
\hline
\end{tabular}

- Какое может быть притяжение, у объекта диаметром 5 сантиметров, к объекту 1,4 метра в диаметре, на расстояние 4550 метров друг от друга. Или, к примеру, взять 14-ти сантиметровый грейпфрут за Солнце, то Нептун будет размером с пяти миллиметровую косточку, на расстоянии 450 метров от грейпфрута. 
Если высчитать силу притяжения к Солнцу для каждой планеты, учитывая расстояние удалённости, размер и орбитальную скорость полёта вокруг Солнца, то будет видно, что закон всемирного тяготения, и общая теория относительности - не работают. Но даже без точного вычисления, взглянув на цифры невооружённым глазом, видно, что астероид Церера при его отдалённости, размере, и скорости, по сравнению с ближайшими планетами: Марсом и Юпитером. - Не, будет хватать силы притяжения, для уравновешивания с центробежной силой, при такой орбитальной скорости. А если сказать кратко: главный пояс астероидов с его мелкими объектами, по сравнению с ближайшими планетами, должен иметь недостаток в силе притяжения к Солнцу, и обязан разлететься по солнечной системе. Но главный пояс астероидов не разлетается, показывая несостоятельность закона всемирного тяготения и общей теории относительности.

Чтоб понять принципы гравитации, необходимо масштабно мыслить! Представим такую ситуацию. - Стоит человек на переднем бампере скоростного электропоезда, прижимаясь к лобовому стеклу. Электропоезд разгоняется до скорости в 500 км/ч. В этой ситуации, человеку будет трудно оторвать спину от лобового стекла, так как его тело, будет придавливаться к электропоезду, встречным воздухом. Хотя, это не встречный ветер, а обыкновенный воздух, которым мы дышим.

Возникает такой вопрос. - Что спереди поезда придавливает, это понятно. А если одновременно: спереди, сзади, по бокам, снизу и сверху, будут находиться люди? Это, я подразумеваю нашу планету. В такой ситуации, только с одной стороны планеты, будет придавливать человека к земле. К тому же, мы не чувствуем своим телом давление гравитации, которое нас придавливает. Но так как всё пространство вселенной, заполнено, так называемым «эфиром» - сверхмалыми частицами. И помимо этого, всё космическое пространство, заполнено фотонами, летящими со световыми скоростями от бесчисленного количества звёзд. То представляем такую модель:

Наша планета вращается вокруг своей оси, и объект, находящийся на поверхности Земли - крутится вместе с планетой. Тем самым, мы получаем пример - как с электропоездом. Вот только на объект находящийся, на земле, давит не воздух (как в примере с электропоездом), а мельчайшие частицы, которые сталкиваются с ядрами атомов объекта, и создают равномерное, постоянное придавливание объекта.

Так как планета вращается не только вокруг своей оси, но ещё вращается вокруг Солнца, то объект, находящийся на поверхности планеты, испытывает на себе, одновременное, двухстороннее давление мельчайших частиц. И это, всего лишь, два одновременных вращения нашей планеты. Но помимо этих вращательных движений, есть ещё:

вращение солнечной системы, в составе рукава Ориона;

вращение галактики, вокруг своей оси - это, вращение рукава Ориона, вокруг центра галактики. 
Есть ещё одно направленное движение всей галактики - это, движение галактики в определённом направлении космического пространства вселенной.

Тем самым, объект, находящийся на планете входящей в состав солнечной системы, движется в космическом пространстве, одновременно в пяти направлениях, испытывая на себе, одновременное давление сверхмалых частиц с пяти сторон. При этом не учитывается возможность движения эфирных частиц, из областей пространства с повышенной плотностью эфира, к области пространства с низкой плотностью эфира. А области пространства вселенной с низкой плотностью эфира образовываются позади движущихся крупных объектов, таких как звёзды и планеты.

Помимо этого, в любой объект солнечной системы, постоянно врезаются фотоны (частицы), летящие со скоростями света от бесчисленного количества звёзд, которые мы можем видеть со всех сторон планеты.

Конечно, ещё предстоит узнать степень влияния на гравитацию: сложных движений планеты в космическом пространстве, и звёздного излучения сверхмалых частиц. Но то, что эти действия создают гравитацию на планетах, я уверен на сто процентов. И утверждаю: Гравитация - это, не тяготение и не притяжение.

Гравитация - это придавливание одного объекта к другому.

Так как в любой объект, а точнее, в каждое ядро атома объекта постоянно и одновременно со всех сторон с космическими скоростями врезаются сверхмалые частицы - создаётся гравитационное давление.

Дальше говоря о гравитации - эти сверхмалые частицы, буду называть «гравитонами», так как они создают гравитацию, и схожи с этим словом по значению. Но это не означает, что они должны иметь это название, так как эти сверхмалые частицы создают не только гравитацию, но и свет, электричество, магнитное поле и т.п. В дальнейшем, когда буду отвечать на вопросы: Что такое электричество? Что такое магнитное поле? Я буду называть по-разному, одни и те же - сверхмалые частицы.

Чтобы более наглядно и понятливее объяснить принцип действия гравитации, нужно в очередной раз обратиться к своему воображению.

Для лучшей наглядности, вообразим объект, находящийся в подвешенном состоянии, на тонкой и длинной нитке, в нескольких метрах от поверхности земли, нашей планеты. И для лучшего понимания всего процесса, необходимо представить не только летящие со всех сторон потоки фотонов. Но и представить в ускоренном виде, все вращательные движения объекта (движения планеты вокруг своей оси; движение планеты вокруг Солнца; движение солнечной системы в рукаве Ориона; движение рукава Ориона вокруг центра галактики; движения самой галактики в космическом пространстве) находящегося в подвешенном состоянии в нескольких метрах от земли. В этом случаи, объект, находящийся над землёй, будет врезаться в гравитоны, одновременно со всех сторон. Но если, из этой модели выделить 
объект и планету, то будет казаться что, не объект и планета врезаются в гравитоны, а наоборот - гравитоны «бомбардируют» объект и планету со всех сторон. Так как гравитоны очень маленькие, то они пролетают между ядер атомов, и только небольшая их часть врезаются в ядра атомов объекта. А так как, планета очень большая и плотная, то большая часть «потока» гравитонов задерживается в нутрии неё. Тем самым, уменьшается плотность «потока» гравитонов летящих со стороны планеты к объекту, чем плотность «потоков» гравитонов с противоположенной стороны объекта. По этому, чем больше размер и плотность планеты, тем больше гравитация (сила придавливания) к этой планете.

Если обратим внимание на то, что на Луне гравитация меньше чем на Земле, то это объясняется тем, что из-за меньшего размера Луны, меньшее количество гравитонов задерживается в нутрии неё. И тем самым, «поток» гравитонов со стороны Луны к объекту, более плотный, и создаёт сопротивление придавливанию объекта к Луне.

К выше сказанному, добавлю: чем больше размер и плотность космического объекта, тем больше гравитонов в центре этого объекта сталкиваются друг с другом, создавая не только высокую плотность, высокое давление, высокую температуру, но и новое вещество. И по этой причине, большие космические объекты растут из нутрии. И такой рост, хорошо заметен, по нашей планете. Континенты нашей планеты, имеют такие формы, что, убрав разделяющие их океаны, континенты можно собрать вместе, в единый сферический континент - как сферическую мозаику (пазлы).

Почему планеты солнечной системы вращаются вокруг Солнца, и не слетают со своих орбит?

- По спиральной траектории, в составе рукава Ориона, Солнце летит в одном ряду с планетами входящими в состав солнечной системы. И так как Солнце, самый массивный объект среди ближайших космических объектов, своим вращением вокруг собственной оси, оно создаёт вокруг себя гравитационное завихрение, и тем самым вращает планеты вокруг себя. Чем ближе планета к Солнцу, тем меньше время оборота вокруг Солнца, и выше орбитальная скорость планеты. А чем дальше от Солнца - соответственно, меньше орбитальная скорость планеты, и больше времени на полный оборот вокруг Солнца. И это закономерность очень хорошо прослеживается:

25,4 суток - Солнце - полный оборот вокруг своей оси.

88 суток - Меркурий - полный оборот вокруг Солнца.........Скорость - 47,9 км/с.

224,7 суток - Венера - полный оборот вокруг Солнца.............Скорость - 35 км/с.

365 суток - Земля - полный оборот вокруг Солния............Скорость - 29,8 км/с.

1,9 года - Марс - полный оборот вокруг Солниа.............Скорость - 24,1 км/с.

4,6 года - Церера - полный оборот вокруг Солнца............Скорость - 17,9 км/с.

11,9 года - Юпитер - полный оборот вокруг Солнца.............Скорость - 13,1 км/с.

29,5 года - Сатурн - полный оборот вокруг Солниа ….........Скорость - 9,7 км/с.

84 года - Уран - полный оборот вокруг Солнца..............Скорость - 6,8 км/с.

164,8 года - Нептун - полный оборот вокруг Солниа............Скорость - 5,4 км/с.

Так вот! Эти выводы - логичны и понятны. 
Но если высчитывать силу «притяжения» (тяготения) для каждой планеты к Солнцу, опираясь на «всемирный закон тяготения и общую теорию относительности», то выходит логическая не состыковка!

Рассчитаем силы «притяжения» (тяготения). Берём за основы:

- диаметр Солнца;

- диаметр планеты;

- орбитальную скорость планеты, вокруг Солнца;

- расстояние между Солнцем и планетой.

Сразу уточняю - почему диаметр, а не массу объекта? - Потому что, диаметр Солнца и планет более-менее точно знаем. А массу планет, не зная, из чего они состоят, и высчитывать, опираясь на гравитационное взаимодействие, практически не зная свойств и принципов гравитации глупо, и несерьёзно! П Поэтому нужно допускать погрешность результата высчитывания силы притяжения планет, из-за разности плотности и масс планет.

Расчёт силы притяжения, планеты к Солнцу - по закону всемирного тяготения:

$\mathrm{F}=\left(\mathrm{v}^{*} \mathrm{~d} 1 * \mathrm{~d} 2 / \mathrm{r}^{2}\right) / \mathrm{x}$

F - сила притяжения планеты к Солниу;

v - орбитальная скорость объекта, вокруг Солниа;

d1 - диаметр Солнциа;

d2 - диаметр Планеть;;

r - расстояние между Солнцем и планетой;

х - число, сокрамающее результат до двухзначного числа с сотыми долями (для лучшего восприятия при сравнении).

Меркурий - F = 96,64 единиц.

Венера - $\mathrm{F}=50,58$ единиц.

Земля $-\mathrm{F}=23,63$ единиц.

Марс - F $=4,38$ единиц.

Церера - F $=0,13$ единии.

Юпитер - $\mathrm{F}=4,20$ единиц.

Сатурн - $\mathrm{F}=0,77$ единиц.

Уран - $\mathrm{F}=0,06$ единии.

Нептун - $\mathrm{F}=0,02$ единии.

Результаты вычисления показывают:

Даже, если допустить разность масс планет в 1-5 раз, то разность сил притяжения планет к Солнцу - разнятся в сотни раз! Тем самым, показывая - Что закон всемирного тяготения и общая теория относительности - не верны!

Учитывая то, что звезда раскручивает вокруг себя планеты, создавая звёздную систему, можно сделать вывод:

Звёздное скопление в центре нашей галактики, создаёт гравитационное завихрение, и раскручивает вокруг себя всю галактику. А некоторые, крайние группы звёзд (центрального звёздного скопления галактики) с одинаковой 
направленностью вращения вокруг своей оси, и направлением своих осей к центру галактики, создают перпендикулярное гравитационное завихрение, раскручивая звёзды и звёздные системы - создавая рукава галактики. А так как, чем ближе объекты к центру галактики, тем выше у них скорость вращения вокруг оси галактики, и меныше занимает времени на полный оборот вокруг центра галактики. Отсюда следует вывод: Рукава галактики постоянно растягиваются удлиняясь. И это растяжение рукавов галактики будет продолжаться подобно тому, как закручивается спиральная пружина в механических часах.

В «Общей теории относительности - А. Эйнштейна», обязательно нужно, чтоб в центре нашей галактики и других похожих галактик, находился объект, с очень большой силой тяготения. - Это нужно для того, чтоб в галактиках, которые вращаются вокруг своей оси, в них не разлетались звёзды и звёздные системы с занимаемых позиций. А так как, этого объекта не существует, но по «закону всемирного тяготения», и «общей теории относительности», он должен быть. То теоретики нашли выход из положения, и выдумали «специальный объект». Но так как его не видно, а точнее - нет, то для него было выдумано свойство, в котором утверждается что у этого объекта настолько сильная гравитация, что даже свет от него не отражается. Поэтому и название такое дали - «Чёрная дыра».

И даже не удивлюсь, если узнаю, что изначально предполагалась, что «чёрная дыра» должна была быть в виде воронки водоворота или чем-то подобным.

Теперь, можно подвести итог по теме гравитации:

Гравитация - это непрерывное, многостороннее столкновение ядер атомов (из которых состоят объекты) с потоками гравитонов (сверхмалыми частицами). При этом между двумя объектами образовывается зона с менее плотными потоками гравитонов, и происходит придавливание объектов друг к другу внешними потоками гравитонов. Сила придавливания (гравитации) объектов друг к другу зависит от масс объектов и расстояния друг от друга.

\section{Кинетическая энергия и перегрузка.}

Что такое кинетическая энергия?

Для понимания процессов здесь также нужно воспользоваться своим воображением.

Возьмём за образец - пулю. Для удобства восприятия, представим её в увеличенном масштабе, и вообразим, что она состоит из очень маленьких шариков (атомов вещества), в центре которых, ещё более маленькие шарики (ядра атомов). 
Мы уже знаем, что потоки гравитонов, врезаются в любой объект, одновременно со всех сторон. Гравитоны представляем как ещё более маленькие шарики, чем ядра атомов пули. Таким образом, получается модель пули, сквозь которую, между ядер атомов, пролетают «потоки» гравитонов. Но определённая часть из них врезается в ядра атомов. Так как эта модель пули неподвижна относительно объектов находящихся на планете, она имеет, только, потенциальную энергию. Т.е. определённо-одинаковое влияние потоков гравитонов на атомы неподвижных объектов относительно объектов находящихся на планете. А относительно других объектов, движущихся в космическом пространстве вселенной на встречу к нашей планете, любой неподвижный объект, находящийся на нашей планете, имеет кинетическую энергию.

Тут же возникает вопрос: А что такое атом?

Атом - это ядро окружённое атомным облаком.

Ядра атомов - это сверхмалые частицы, плотно соединённые в один объект, и имеют: разную массу, размеры, плотность и скорость вращения вокруг своей оси.

Атомное облако - это область, окружающая ядро атома, состоящая: из непрерывно врезающихся, пролетающих рядом, или отражённых сверхмалых частиц, от вращающегося ядра атома. Размер, плотность и завихрение атомного облака зависит от размера и плотности ядер атомов и от скорости вращения ядра вокруг своей оси.

Теперь продолжим с моделью пули...

Как только, пуля начнёт свой полёт, сразу увеличится количество гравитонов содержащихся в атомном облаке, со стороны, в которую летит пуля. Тем самым, будет увеличиваться плотность атомного облака, и соответственно кинетическая энергия. Чем больше масса и скорость пули, тем больше кинетическая энергия. По мере замедления пули постепенно уменьшается кинетическая энергия, рассеиваясь в окружающей среде. Но если, пуля с высокой скоростью полёта, столкнётся с препятствием, то накопленные гравитоны (кинетическая энергия) в атомах пули, перейдут к препятствию, с которым столкнулась пуля. И резко рассеваясь в препятствии, моментально передастся кинетическая энергия (накопленные гравитоны), а при очень высокой скорости полёта пули, накопленные гравитоны будут разрывать атомные связи препятствия, и самой пули.

К кинетической энергии, также имеет отношение - так называемая «перегрузка», которую чувствуют своим телом пилоты при резком ускорении движения, или резкой смене вектора движения. Увеличивая в своём теле количество и давление гравитонов (кинетическую энергию) содержащихся в атомах тела пилота со стороны, в которую движется пилот до момента ускорения до постоянной скорости движения. Т.е., до момента равномерного 
распределения гравитонов в атомах тела пилота, при постоянной скорости движения.

\section{Антигравитация.}

«Если знаешь приниип проблемь, с которой сталкиваешься, то проще найти, как с ней справиться».

Зная принцип действия гравитации, можно поразмыслить, как с ней бороться.

Так как, гравитация - это придавливание потоками гравитонов одного объекта к другому. Это означает, что объект, находящийся на земле, нужно защищать от внешних потоков гравитонов, чтоб уменьшить силу придавливания к планете. Под внешними потоками гравитонов, подразумевается не только строго вертикальные потоки, но и те, которые летят к центрам объектов под определёнными углами.

Для того чтобы создать антигравитационный аппарат, нужно внешние потоки гравитонов, перенаправить в другую сторону от объекта.

Мы знаем, что при увеличении скорости движении объекта, увеличивается кинетическая энергия. А кинетическая энергия - это захват и перенос гравитонов движущимся объектом.

К тому же, электрический ток, тоже перенаправляет потоки сверхмалых частиц из области высокого давления в область низкого давления.

Так что, для создания антигравитациорного аппарата, нужно:

1. В верхней части аппарата, нужно установить устройство, над которым будет вращаться с высокой скоростью диск. Диск должен состоять из тонких, высоко-проводящих электрический ток металлических пластин, разделённых между собой тонким слоем диэлектрика. Возможно, понадобиться устанавливать друг над другом, несколько таких дисков, с разными диаметрами, и разными скоростями вращения. Так как в центре большого диска будет недостаточная скорость вращения.

2. На диск нужно подавать постоянный электрический ток, с направлением от центра диска к его краям.

3. На диск необходимо подавать микро-удары высокой частоты. Это нужно для того, чтобы не увеличивалось скопление и давление гравитонов в атомах диска со стороны центра диска. - Т.е. при высокой частоте вибрации ядер атомов диска не будет больших скоплений гравитонов в атомах диска, и сильного давления на эти ядра атомов.

Таким образом, раскручивающийся диск до высокой скорости не должен в себе сильно увеличивать кинетическую энергию, а будет с помощью центробежной силы и постоянного тока, перенаправлять потоки гравитонов 
от центра диска к его краям, и дальше по направлению не задерживаясь на краю диска. А потоки гравитонов, с нижней стороны антигравитационного аппарата давя на корпус, двигатель диска, и остальные объекты, находящиеся под диском - будут двигать антигравитационный аппарат снизу вверх. То есть, это не только антигравитационный аппарат, но и гравитационный движитель.9

«Не получается что-то сделать, у того - кто никогда ничего сделать не nробуеm!»

\section{Электричество и магнетизм.}

Что такое электрический ток?

Пока не узнаешь принцип гравитации, и что собой представляет атом, то можно только гадать над вопросом принципа и свойств электрического тока. Так как, мы уже знаем об этом, то можно начать разбираться с вопросом об электрическом токе. Вот только, чтоб разобраться в принципах электрического тока - необходимо вместе с этим, разбираться и с магнетизмом.

Почему южные полюса магнитов отталкиваются друг от друга?

Ссылаясь на школьную программу - можно понять так: Северные полюса магнитов отталкиваются друг от друга, из-за того, что из северного полюса постоянного магнита, выходят линии магнитного потока (линии магнитной индукции). - Поэтому, два встречных магнитных потока отталкивают северные магнитные полюса друг от друга. Но почему южные полюса магнитов, точно также отталкиваются друг от друга. С логической точки зрения, южные полюса магнитов должны притягиваться друг к другу, как концы шлангов от двух пылесосов. - Из-за того, что, в южные полюса постоянного магнита, входят линии магнитного потока. Как минимум, должна быть разница в силе отталкивание, между полюсами: «северныйсеверный» и «южный-южный».

Так же. Почему электроны не слетают со своих орбит? Если под воздействием магнитного поля, в проводнике электроны начинают двигаться, то почему, электрон, слетая со своей орбиты, занимает чужую орбиту, и не слетает с неё? Хотя, сила «перекинувшая» электрон с одной орбиты на другую орбиту рядом находящегося атома должна изменить орбитальную скорость движения электрона. Тем самым, нарушив равновесие между силой притяжения электрона к ядру атома и орбитальной скоростью электрона, должно привести к покиданию его с расположенных орбит вокруг атома.

Это конечно, если опираться на «закон всемирного тяготения» и «общую теорию относительности». И при этом довериться теории планетарного строения атома... 
Также, нет внятных объяснений, про положительные и отрицательные частицы.

«Принимая за истину: знания с логическими ошибками, мы неправильно формируем структуру развития своего логического мылиления, $u$ поворачиваемся в сторону тупиковой ветви развития».

Попробую дать логически обоснованные ответы, опираясь на факты:

Основным устройством по выработки электроэнергии, является электрогенератор. - С него и начнём.

Генераторы, вырабатывают постоянный или переменный электрический ток. А что общего у постоянного и переменного тока? - То, что способ получение электрического тока, будь то постоянный, или переменный - он, одинаковый. Так как в обмотках генератора - ток переменный. А постоянным током становится, после прохождения через щёточноколлекторный узел, или диодный мост.

Для выработки электрического тока в генераторе необходим постоянный магнит или электромагнит. Для электромагнита необходим электрический ток! Для намагничивания постоянного магнита необходим электрический ток! - Получается замкнутый круг. И чтобы разобраться с «замкнутым кругом», нужно найти общую составляющую этого «круга». Общее у постоянного магнита и электромагнита - это магнитное поле.

Думаем дальше... - Что, и каким образом, может двигаться по электрическому проводнику (по электропроводам) со скоростью, приближённой к скоростям света? - Примерно таким же образом, свет движется по волоконно-оптическому кабелю.

Так как, постоянные потоки сверхмалых частиц со скоростями света летят от бесчисленного количества звёзд в разные стороны. То получается, что в каждый объект, в том числе, и каждое ядро атома, постоянно врезаются со всех сторон, сверхмалые частицы. И для того, чтобы получить электрический ток, нужно разнонаправленные потоки сверхмалых частиц, сконцентрировать в один поток, и направить в нужном для нас направлении.

Полагаю, что так называемые «электроны» - это сверхмалые частицы, двигающиеся направленными потоками, от области высокого давления к области низкого давления. - А области давления создаются магнитными полями.

Теперь по подробнее:

Постоянный магнит - это кусок материала с определённой кристаллической (атомной) решёткой. Где все ядра атомов раскручены в одну сторону (имеют одинаковый спин) в сильном магнитном поле, созданным катушкой индуктивности.

Магнитное поле магнита - это разнонаправленные потоки сверхмалых частиц, закрученные в вихрь, которые не только влетают в вихрь, но и вылетают из него. Точнее - один вихрь, состоящий из более маленьких 
вихрей, раскрученных однонаправлено вращающимися (с одинаковым спином) ядрами атомов магнита.

Магнитные полюса магнита - это направление вращения магнитного поля (вихря, состоящего из множества ещё, более меньших вихрей, созданных вращением ядер атомов магнита).

Таким образом, объясняется, «почему одноимённые полюса магнитов отталкиваются друг от друга, а разноимённые притягиваются?». Так как, два магнита направленные друг к другу разноимёнными полюсами, образовывают из двух магнитных полей (вихрей) один магнитный вихрь (магнитное поле). То, магниты, направленные друг к другу одноимёнными полюсами, отталкиваются друг от друга, из-за того, что два разнонаправленных магнитных вихря не могут объединиться в один.

Что происходит в обмотках генератора при разомкнутой цепи?

Когда, на последовательно соединённые катушки, наводятся магнитные вихри однонаправлено закрученные, то, от одного вывода катушки к другому выводу последовательно соединённой катушки, образовывается сконцентрированный в проводнике поток сверхмалых частиц, создающий на одном конце проводника - область повышенного давления, а на другом область пониженного давления.

Соответственно, при смене полярности, т.е. смене направленности магнитных вихрей - область повышенного давления меняется местами с областью пониженного давления.

Плюс и минус, под которыми подразумевается положительный и отрицательный заряды - это области высокого давления и низкого давления. Можно сказать ещё так - область с высокой плотностью и область с низкой плотностью сверхмалых частиц.

Почему вокруг проводника с постоянным током, образуется магнитное поле?

- Ещё раз повторю! - Так как, постоянные потоки сверхмалых частиц со скоростями света летят от бесчисленного количества звёзд с разных сторон. То получается, что в каждый объект, в том числе, и каждый атом, постоянно врезаются со всех сторон, сверхмалые частицы. Таким образом, сверхмалые частицы, летящие сквозь атомы проводника, попадают в однонаправленный поток электронов постоянного тока. Многие сверхмалые частицы подхватываются потоком электронов, а некоторая их часть, сталкиваясь с потоком, меняет своё направление движения под определёнными углами в сторону движения постоянного потока электронов. И в зависимости от параметров постоянного тока, образуется на всю длину проводника подобие «вихря», который затягивает пролетающие рядом с проводником сверхмалые частицы. 
В своей теории, я использую всем известные названия элементарных частиц, для того, чтоб не создавать путаницы:

- гравитон - это частица гравитации;

- фотон - это частица света;

- магнетон - это частица магнитного поля;

- электрон - это частица электрического тока.

И под этими названиями элементарных частиц, я подразумеваю - что эти элементарные частицы состоят из групп сверхмалых частиц с определёнными свойствами и характеристиками - как у групп, так, и у сверхмалых частиц. К свойствам и характеристикам частиц относится: масса, объём, форма, плотность, направление вращения (спин), скорость вращения и скорость движения.

На примере с лампой накаливания, объясню принцип действия электрического тока, и как из электронов происходят фотоны:

В очередной раз повторю: Так как, постоянные потоки сверхмалых частиц со скоростями света летят от бесчисленного количества звёзд с разных сторон. То получается, что в каждый объект, в том числе, и каждый атом, постоянно врезаются со всех сторон сверхмалые частицы.

И вот ещё одно логическое доказательство:

Берём небольшой электрогенератор, и на его мощность подключаем несколько ламп накаливания. После запуска электрогенератора, он может работать годами. И всё это время лампы накаливания будут испускать свет и тепло. Вот тут, и возникает вопрос - Откуда берётся энергия, которая излучается в виде света и тепла, если по электрической цепи генератора и ламп накаливания туда-сюда гоняются так называемые «электроны»?

Поэтому, я убеждён в том, что:

Электрический ток - это потоки сверхмалых частиц (летящие со скоростями света), сконцентрированные в один поток, направленный из области высокого давления к области низкого давления при помощи магнитных полей (магнитных вихрей).

Но тут возникает вопрос. - Почему нужно крутить электрогенератор, чтоб постоянно менялись полюса магнитов на катушках, а не зафиксировать магниты напротив катушек, создавая непрерывный поток электронов?

Если резко поднести магнит к катушке индуктивности и не убирать его, то измерительный прибор покажет одиночный импульс. Это означает то, что электрический ток - это не постоянно сконцентрированный поток электронов созданный при помощи проводника смотанного в катушку и магнитных вихрей магнитов.

Электрический ток - это подобие перегрузки при ускорении до определённой постоянной скорости сконцентрированного потока сверхмалых частиц (электронов). О перегрузки и кинетической энергии описано выше. 
Электрический ток - это резкое появление потока сверхмалых частиц (электронов) двигающихся по проводнику от области высокого давления к области низкого давления, нарушая обычное состояние атомов проводника. Тем самым, создаётся давление на ядра атомов в проводнике со стороны высокого давления создаваемого магнитным вихрем. И это длится практически со световой скоростью до того момента, пока атомы проводника не приобретут определённое, равномерное давление, и плотность сверхмалых частиц.

Теперь можно ответить на вопрос - «Почему спираль электрической лампы накаливания нагревается и испускает свет?».

При резком продвижении плотного потока электронов сквозь атомы спирали лампы, у которой пропускная способность намного меньше чем у проводника. Создаётся ещё более плотный поток, электроны которого, врезается с ещё большей интенсивностью в ядра атомов спирали. Тем самым, создавая не только подвижки ядер атомов, но и при столкновении на световых скоростях электронов с ядрами атомов, создаются реакции с выбросом энергии в виде тепла и света. А при мощных токах как в электросварочных аппаратах - там постоянный (однонаправленный) ток, при коротком замыкании, срывает крайние атомы электрода, перенося их с области высокого давления в область с низким давлением.

\section{Время.}

Время - это функция, указывающая на местоположения движущегося объекта в пространстве вселенной, обеспечивающая вычисление местонахождения объекта в определённом промежутке времени. Зная параметры, скорость и направление движения объекта, и учитывая влияние окружающей среды, и вариативность последовательности событий, можно вычислить траекторию дальнейшего движения, или местонахождения объекта в определённом промежутке времени.

Так как, во вселенной нет «области покоя», где не происходит никаких движений, то и нет места, где нет течения времени. Этим доказывается то, что с какой бы ты световой скоростью не передвигался бы, то, это не означает, что ты ускоряешься во времени - это означает, что ты двигаешься быстрее, чем остальные объекты вселенной.

А чтобы вернуться в прошлое хотя бы на одну минуту назад, то нужно вернуть назад на одну минуту, все объекты (от самой маленькой элементарной частицы, летящей от звезды со скоростью света, до всех галактик) которые постоянно двигаются с космическими скоростями в пространстве вселенной.

Нужно понимать, что ты не являешься центром вселенной, ты всего лишь микроскопическая частица этой вселенной, которая создана и существует в бесчисленных движениях вселенной. И нет такой силы, чтобы развернуть 
ВСЁ происходящее движение вспять. Так как, невозможно сделать так, чтобы звёзды не излучали фотоны света, а впитывали их обратно в себя из окружающего пространства.

Если гипотетически повернуть движение ВСЕХ сверхмалых частиц вспять, то пропадут все межатомные связи...

Сразу отвечу на такой вопрос: «Но как же эффект с разностью течения времени на земле и на космической станции на орбите? Кем-то зафиксировано, что на космической станции из-за высокой скорости, время движется чуть медленнее, чем на земле».

- Это также глупо утверждать, как и то, что если механические часы поместить в помещение с высокой температурой, и утверждать, что там время замедляется. А в помещение с низкой температурой, утверждать, что время ускоряется.

Разница в тысячные доли секунды, замеченные за пол года, возможна по причине влияния перегрузки на часы, когда доставлялись на космическую станцию. Или некорректное снятие показаний. Но вероятнее, основной причиной, является влияние окружающей среды на атомные часы. Так как, силы гравитации на земле и на космической станции разные.

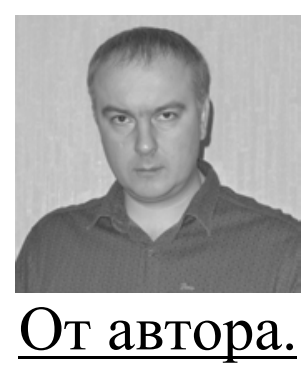

В моём научном докладе «Общая теория мироздания» излагая свои мысли и теории, я намеренно не давал новых названий, чтоб не было путаницы. Старался подбирать слова подходящие по смыслу и значению.

Возможно, кто-то не всё поймёт, что я описывал в этом докладе, из-за того, что я не стал перегружать информацией, и более подробными пояснениями.

Думаю, что появятся ко мне вопросы об уточнениях некоторых деталей, по моим теориям, которые описывал в максимально сжатом состоянии. И после формирования вопросов и уточнений, статью «Общая теория мироздания» придётся дополнять уточнениями, и пояснительными рисунками.

02.03.2016 г.

Автор доклада, Малюгин Дмитрий Васильевич, 26.06.1980 года рождения. Исследователь фундаментальных физических законов и явлений. Теоретик. Россия, г. Ростов-на-Дону. mysliteli@bk.ru 
